\title{
Development of Multifunctional Anti Aging Military Raincoat Fabric by
}

\section{Using Fitting Technique}

\author{
Chun Xia CHEN
}

Yan cheng institute of industry College, Yan cheng, Jiang su 224005; Excellent Scientific and Technological Innovation Team of Jiangsu Province 2015; chx9941@126.com

\begin{abstract}
Use Woodland camouflage paint Oxford fabric as base cloth, first the light pressure processing was used on the fabric, and then use polyurethane which has high water vapor permeability performance and other various additives as face glue and Bottom glue, the fabric was compounded a thin macromolecule hydrophilic polymer PU film, the fabric was water allocation processed after stripping, At last the fabric will have high performance of the windproof, waterproof and moisture permeability. After testing, the performance index of the fabric are: the smoothness appearance of fabrics after cleaning $\geq$ grade 4.0 ; hydrostatic pressure $\geq 10000 \mathrm{mmH}_{2} \mathrm{O}$, after 20 times washing $\geq 5000 \mathrm{mmH}_{2} \mathrm{O}$; The surface water repellency level $\geq$ grade4.0,after 20 times washing $\geq$ grade 3.0 ; water vapor permeability $\geq 3500 \mathrm{~g} /\left(\mathrm{m}^{2} \cdot 24 \mathrm{~h}\right)$; Electrostatic charge density $\geq 2.5 \mathrm{uc} / \mathrm{m}^{2}$; humid air accelerated aging grade $\geq 4.0$. Test data shows that the designed functional fabric meet the technology requirement of the standards, meet the demand of the customer's use requirements.
\end{abstract}

Keywords: Fitting Technique; raincoat fabric; design; properties; test;

Top-notch Academic Programs Project of Jiangsu Higher Education Institutions 2015

With the economic development and The continuous improvement of people's living standard, fabric and clothes continuously extended in practice, gradually formed a special fabric finishing technology. Especially the development of advanced science and technology, People proposed higher and higher、 more and more requirements for textiles' performance. And the high waterproof and high moisture permeable fabrics were popular.

\section{Experiment}

\subsection{Fabric specifications}

Width: $150 \mathrm{~cm} \quad$ Warp:

150D polyester filament (FDY)

Weft yarn: 150D polyester filament (FDY)

Warp and weft density: 480 roots $/ 10 \mathrm{~cm} \times 430$

roots $/ 10 \mathrm{~cm}$;

\section{Technological process}

base cloth $\longrightarrow$ light pressure

face glue configuration $\longrightarrow$ release paper gluing $\longrightarrow$ drying $\longrightarrow$ cooling $\longrightarrow$ bottom side gluing $\longrightarrow$ semi drying

Weight: $150-160 \mathrm{~g} / \mathrm{m}^{2}$

Fabric weave: $2 / 2$ twill

1.2 Choice of raw materials:

release paper

High moisture permeable polyurethane (solid content $30 \sim 55 \%$ )

solvent (two methyl amide DMF, butanone

MEK, toluene TOL)

Desiccant, curing agent, promoting enzyme, color paste, etc.

\subsection{Equipment}

The production equipment of Multifunctional Anti Aging Military Raincoat Fabric is provided by jiang su nanwei Yueda, The equipment consists of the following parts: surface Glue table、 oven、Bottom glue table、 Laminating device and winding device 
$\longrightarrow$ fitting $\longrightarrow$ cooling $\longrightarrow$ winding $\longrightarrow$ ripening $\longrightarrow$ peeling $\longrightarrow$ Water allocation processed

\section{$\longrightarrow$ drying $\longrightarrow$ end product}

\section{1 pretreatment process}

The pretreatment process of base cloth are generally light pressure and water allocation, Considering the adhesion fastness between Oxford cloth and PU film, select the light pressure pretreatment on the base cloth, Considering the requirements of water resistance and moisture permeability index , water allocation finishing is processed after stripping. 2.2 transfer and fitting

This project uses the release paper transfer and fitting process. The process shown in figure 2-1:

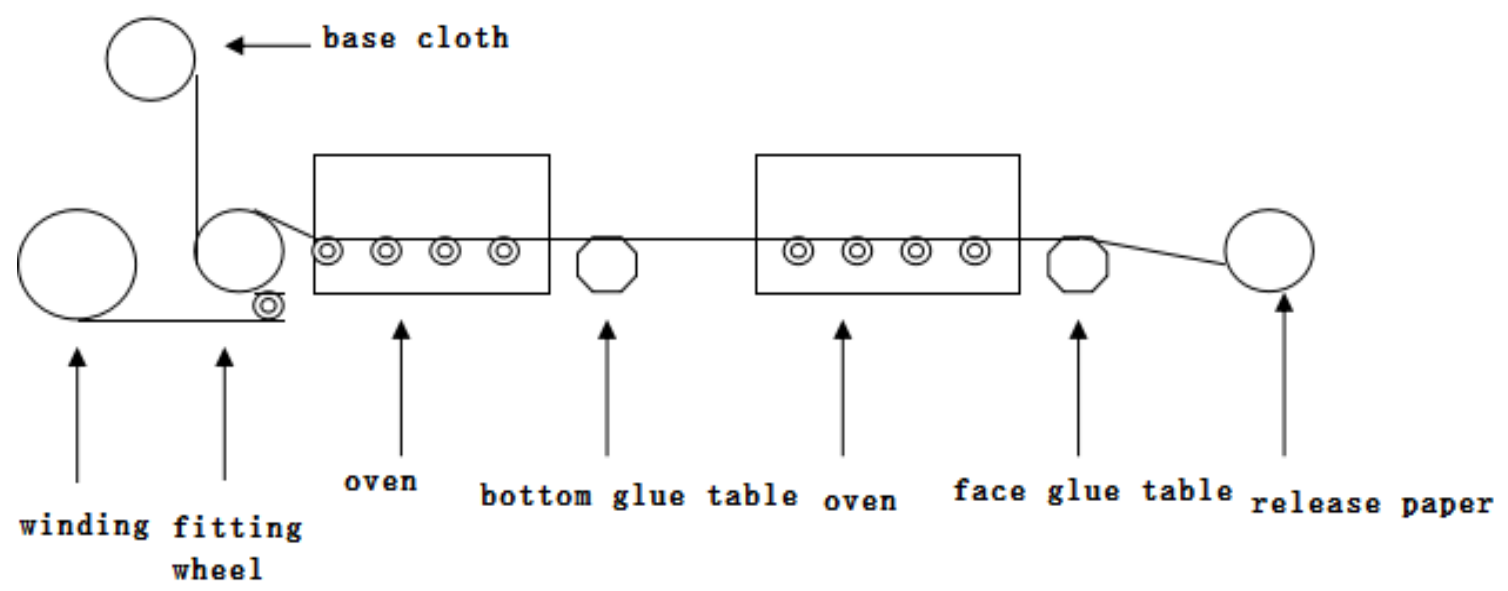

Figure 2-1 Transfer and Fitting process

\subsection{Ripening process flow}

In order to improve adhesion fastness. After transfer and fitting the fabrics are send to the ripening room, in the environment of $65^{\circ} \mathrm{C}$, ripen 48 hours.

2.4 Water allocation process flow

The specific process flow shown as below:

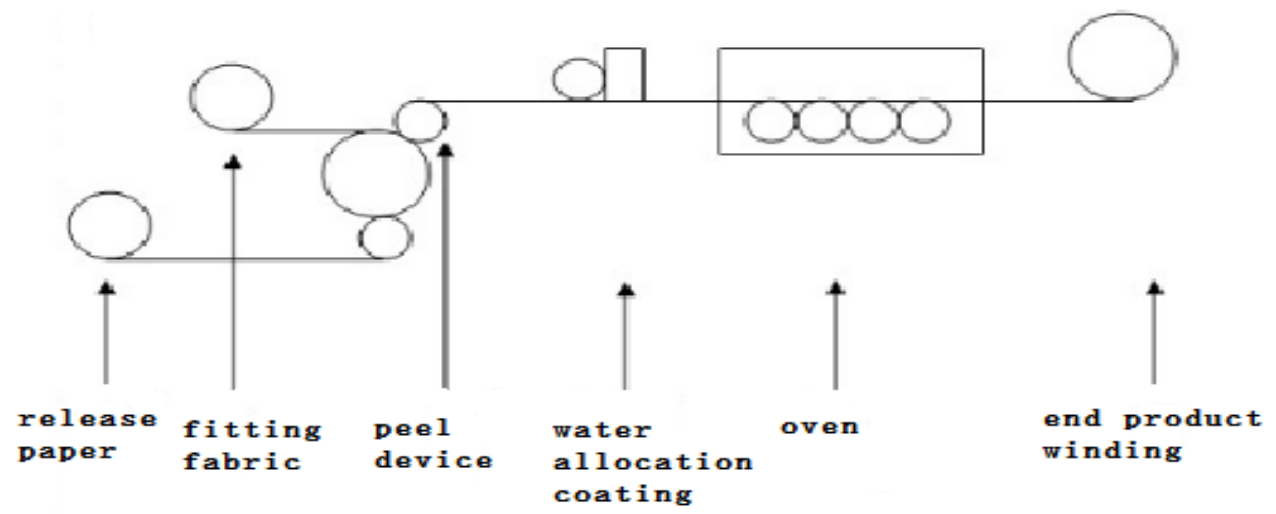

Figure 2-2 Water allocation process flow

\section{Process parameters and key technologies}

\subsection{Glue formula and viscosity control}

The goal of this project is to produce high moisture and high waterproof raincoat fabric, The product is processed by using the single component Solvent type high moisture permeable polyurethane as the surface layer of the fabric. Because the composite base fabric is thin and light, Slip and anti blocking properties should be better for the single component polyurethane.

The tensile modulus of the standard skin coating should be about $8 \mathrm{MPa}$ when the elongation is $100 \%$. According to the fabric specification the surface glue viscosity is $3000-4000 \mathrm{cps}$, the bottom glue viscosity is 
4000-5000cps, The glue formula is as follows:

Table 3-1 Glue formula

\begin{tabular}{ccc}
\hline Reagent & Face glue & Bottom glue \\
\hline PU resin & 100 (Solid content 30\%) & 100 (Solid content 55\%) \\
solvent & $40--80$ & $40-60$ \\
auxiliaries & $1---2$ & \\
Bridging agent & & $6--8$ \\
Promoters & & $1--2$ \\
\hline
\end{tabular}

\subsection{The gluing quantity and laminated pressure}

The test shows that the surface layer thickness increase that is the increase of coating amount. Abrasion resistant and strength also increased. But the water vapor permeability decreased; when The Link layer thickness increased can increase the peeling strength, but effect the moisture permeability and handle. Coating thickness determines the PU coating agent amount, also an important factor which determine the product's cost. According to the fabric specifications, the coating thickness is $18-20 \mu \mathrm{m}$ 。If the pressure is small, although the handle is good but it will result in no laminating or weakly laminated, If the pressure is too big, the fabric and substrate 's compression deformation will increase and the handle will become hard or stiff. For this product the laminated pressure is about $4.5 \mathrm{Kg}$.

3.3 drying temperature, time and air volume Solvent ratio, drying temperature, vehicle speed, air volume and so on are the important factors that affect the film forming properties of polyurethane, It is also an important factor affecting the waterproof and moisture permeability of fabric . If the film formation temperature is high, the solvent evaporation rate will be fas, And accelerate the movement of polymer molecular chain segment, also can raise the generating efficiency and improve the permeability. But when the speed is too high, the heating rate is too fast, Can cause the film surface temperature rise too fast, make the polyurethane film crack and generate air hole. Reduce the waterproof performance. This product use the stage heating mode drying when the temperature up to $80{ }^{\circ} \mathrm{C} \sim 120{ }^{\circ} \mathrm{C}$. Speed is also an important factor affecting the film formation and fitting. If the Speed is too fast, the film formation won't be good and it is easy to produce bubbles. At the same time, the glue viscosity is insufficient, the fastness is poor, feel hard. Generally the speed is slower controled, Film formation speed is $10 \sim 15 \mathrm{~m} / \mathrm{min}$, fitting speed is $20 \sim 25 \mathrm{~m} / \mathrm{min}$.

\subsection{Ripening temperature and time determination}

Since it is a semi dry lamination, So the curing effect of connecting layer depends on the ripening temperature and time, For this product the ripening temperature and time: $65^{\circ} \mathrm{C}, 48 \mathrm{~h}$. This condition can completely cure products, and enhance the peel strength.

\section{Performance test}

The Products were produced by Jiangsu Nanwei Yueda Fiber Technology Co.Ltd and were sent to CNTAC Testing Center-Suzhou Zhongke Textile Technology Service Co.Ltd. The Test standards and the corresponding index and test results are shown in the table 4-1. 
Table 4-1 Testing Results

\begin{tabular}{|c|c|c|c|}
\hline Item & Standard & Index & Result \\
\hline Washing appearance & GB/T13769-2009 & 10 times washing $\geq 4.0$ grade & $\begin{array}{c}10 \text { times washing: } \\
\text { 4. } 0 \text { grade }\end{array}$ \\
\hline Hydrostatic pressure & GB/T 4744-2013 & $\begin{array}{c}\geq 10000 \mathrm{mmH}_{2} \mathrm{O}, \text { after } 20 \text { times } \\
\text { washing } \geq 5000 \mathrm{mmH}_{2} \mathrm{O}\end{array}$ & 14760,5671 \\
\hline $\begin{array}{l}\text { Surface water } \\
\text { resistance }\end{array}$ & GB/T4745-2012 & $\geq 4.0$ grade, after 20 times washing $\geq 3.0$ grade & $4-5$ \\
\hline $\begin{array}{c}\text { Moisture } \\
\text { permeability }\end{array}$ & GB/T12704.1-2009 & Moisture permeability rate $\geq 3500 \mathrm{~g} /\left(\mathrm{m}^{2} \cdot 24 \mathrm{~h}\right)$ & 3990 \\
\hline Anti static & GB/T 12703-2009 & $\geq 2.5 \mathrm{uC} / \mathrm{m}^{2}$ & 2.8 \\
\hline Ageing resistance & FZ/T75007-1995 & $\geq 4.0$ grade & $4-5$ grade \\
\hline
\end{tabular}

Test data from table 4-1show hat the designed product's performance on Washing appearance、 Hydrostatic pressure、Surface water resistance、 Moisture permeability and anti static Ageing resistance have all reached technical requirements of the standards, meet the requirements of the normal customers, fulfill the original intention of the design.

\section{Conclusions}

Multifunctional anti aging military raincoat Fabric, Use Woodland camouflage paint Oxford

\section{References}

[1]GB/T 13769-2009 Textiles-Test method for assessing the smoothness appearance of fabrics after cleaning $[\mathrm{S}]$.

[2]GB/T 4744-2013Textiles-Testing and evaluation for water resistance-Hydrostatic pressure method.

[3] GB/T4745-2012 Textiles-Testing and evaluation for water resistance-Spray test method.

[4]GB/12704-2009 Textiles-Test method for water-vapour transmission of fabrics.

[5]GB/T 12703-2009 Textile-Evaluation for electrostatic propertie-part 2:Electric charge desity.

[6]FZ/T75007-1995Testing Method for Accelerated Ageing of Coated Fabric under Hot and Damp Air Conditions fabric as base cloth, The Multifunctional fabric is the preferred material for making the military raincoat, the mountaineering clothes and the ski clothes. The product has the performance of windproof 、 waterproof 、 and high moisture permeability which ensure the product having competitive advantage in the market. The development of this product can improve the competitive advantage of the enterprise, It is of great significance to promote the product export and to improve the product value added.

[7] WANG Chun-mei, LI Zhao-hui. Analysis of factors affecting performances of waterproof \& moisture permeable laminated fabric[J].SHANGHAI TEXTILE SCIENCE\& TECHNOLIGY, 2009, 37(7): 52-53. 